\title{
Synthesis and Characterization of Carbon Nanotubes Using Amorphous Alloy Catalysts
}

Nahla Ismail, I.H. Abdel-Maksod and A. A. A. Badawy

Physical Chemistry Department, Center of Excellence of Advanced Science, National Research Center, Cairo, Egypt.

\begin{abstract}
RC DISCHARGE method was utilized to synthesize carbon nanotubes (CNTs). The arcing was carried out in air atmosphere in presence of amorphous alloy as catalyst. The current density was maintained constant during the experiment. The amorphous alloys used were $\mathrm{CoFeB}$ amorphous alloy and $\mathrm{ZrCuNiAl}$ amorphous alloy. Characterization of the samples produced indicates that the presence of $\mathrm{CoFeB}$ amorphous alloy much enhanced the yield of multiwall carbon nanotubes (MWNTs). In contrast, the use of $\mathrm{ZrCuNiAl}$ amorphous alloy exerted an opposite effect. The produced MWNTs were tested for hydrogen sorption at 20 bar.
\end{abstract}

Keywords: Carbon nanotubes, Amorphous alloy, Hydrogen sorption .

Since the discovery of CNT in 1991 when Iijima in $1991^{(1)}$ published TEM-figures of "microtubules of graphitic carbon" which were seen in the ashes of an arc-discharge experiment and latter on named CNT. Since that time, scientists focused on that new branch field of material science due to its extraordinary properties. The discovery of these magnificent materials is considered as $21^{\text {st }}$ century material. Different types of CNT could be prepared by different methods. These types are named according to the number of inner walls of CNTs formed. They are either single wall (SWNT) or double wall (DWNT) or multiwall (MWNT). Their methods of preparation are via arcdischarge or laser ablation or chemical vapor deposition ${ }^{(2-4)}$. The type of CNT and the tube diameter are selective to the catalyst used, for example $\mathrm{Ni}, \mathrm{Co}$ and $\mathrm{Fe}$ are known to be used for production of SWNT and DWNT. On the other hand, the yield is dependent on the method so that arc-discharge produces large scale of CNTs rather than the laser ablation and CVD methods. It has extraordinary properties, e.g. tensile strength up to $100 \mathrm{GPa}$, unique current carrying capacity, deformability, Young's modulus up to $1 \mathrm{TPa}$ and field emission at $1-3 \mathrm{~V}^{(5,6)}$.

CNTs have been studied for the importance of their potential applications in various fields, namely electronic devices ${ }^{(7)}$, activated fiber and probe for atomic force microscopy ${ }^{(8)}$, strong reinforcement for composite materials ${ }^{(9)}$, for hydrogen storage ${ }^{(10)}$ and recently in PEM membrane ${ }^{(11)}$.

Our aim is to synthesize CNTs by arc-discharge under convenient conditions for scale applications, so that pressurized helium is replaced by atmospheric air pressure. Amorphous $\mathrm{CoFeB}$ was utilized as a new catalyst for quantitative CNTs production. 


\section{Arcing method}

\section{Experimental}

The AC/DC power supply unit inverter utilized in the preparation of carbon nanotubes was carried out using arc discharge process, with a DC power supply providing $150 \mathrm{Acm}^{-2}$ current density and $36 \mathrm{~V}$. Graphite rod with diameter $11 \mathrm{~mm}$ (99.7\% purity) was used as anode for arcing. The catalyst was inserted in the hallow space in the middle region of the rod. The hallow space is of $6 \mathrm{~cm}$ length and $6 \mathrm{~mm}$ diameter.

Arcing was carried out with a graphite disc as cathode electrode. A thick copper metal plate holds the graphite cathode disc. Cooling of cathode carbon disc takes place during arcing process. The arcing time was $30 \mathrm{sec}$. Then it stopped for two minutes to remove the deposited soot on the graphite disc by a thin blade that scrapped the cathode by applying rotation. By this technique the cathode was maintained free of deposited material which is removed from the high temperature reaction region. All experiments were carried out in open air.

Soot produced was crushed using mortar and pestle to obtain fine powder. Part of this fine crushed powder was heated in open air in a closed furnace at $550{ }^{\circ} \mathrm{C}$ for $2 \mathrm{hr}{ }^{(12,13)}$ and washed by toluene.

\section{Instruments}

After purification, X-ray powder diffractograms were carried out using (Bruker D8 advance target) the scaning rate was fixed at $8^{\circ}$ in $2 \theta \mathrm{min}^{-1}$ for phase identification after each preparation. The patterns were run with CoK $\alpha$ with secondly monocromator $(\lambda=0.179 \mathrm{~nm})$ at $40 \mathrm{kV}$ and $40 \mathrm{~mA}$. Raman Spectroscopy with excitation energy of $10 \mathrm{~mW}$ and a wavelength of $514 \mathrm{~nm}$ was used.

The morphology of each sample of CNTs was examined by scanning electron microscope (SEM). The photographs were obtained using SEM Model S 150 A Sputter coater (Edwards, Germany).

All samples were spread over a double face scotch tape attached to the holder and sputtered with gold and imaged via " Jeol, JXA-840 A electron probe microanalyzer " at $30 \mathrm{KV}$.

Thermal gravimetric analysis (TGA) curves were obtained simultaneously through measurements carried out by an apparatus "DSC Q 600"-V 20.5-USA under air flow.

About $10 \mathrm{mg}$ of each sample was heated gradually from room temperature using heating rate of $10^{\circ} \mathrm{C} / \mathrm{min}$ in a current of pure nitrogen flowing at a rate of $20 \mathrm{ml} / \mathrm{min}$.

\section{Amorphous alloys preparation}

The amorphous $\mathrm{Zr}_{55} \mathrm{Cu}_{30} \mathrm{Al}_{10} \mathrm{Ni}_{5}$ alloy was prepared as ribbons by rapid quenching as had been explained before in literature ${ }^{(14)}$. While the amorphous $\mathrm{Fe}_{45.6} \mathrm{Co}_{17.9} \mathrm{~B}_{36.5}$ powder was obtained by chemical reduction adopting the method suggested by Inoue et al. ${ }^{(15)}$. The samples were proved to be fully amorphous by XRD. 


\section{Hydrogen sorption method}

The hydrogen sorption measurements of CNTs were determined using Pressure Composition Temperature Isotherm (AMC PCI-HP-1200). Each sample of $100 \mathrm{mg}$ was degassed at $100{ }^{\circ} \mathrm{C}$ under dynamic vacuum for one hour before carrying out any measurement to remove any air contaminations.

The sorption measurements were carried out up to 20 bar applied hydrogen pressure, where the amount of hydrogen adsorbed is plotted versus time. The accuracy of hydrogen capacity measurements are $\pm 0.04 \mathrm{wt} \%$.

\section{Results and Discussion}

After the arc plasma process utilized in air atmosphere under atmospheric pressure, the soot mounted on the cathode was collected in each experiment and examined. Figure 1 shows the SEM image of the raw sample without using a catalyst and before purification. There are two main components, carbon nanotubes (CNT) and carbonaceous particles.

Figure 2 presents the SEM image of CNT produced in presence of amorphous $\mathrm{FeCoB}$ as a catalyst without purification. The image reveals the 3 components, CNTs, carbonaceous particles and catalyst white particles.

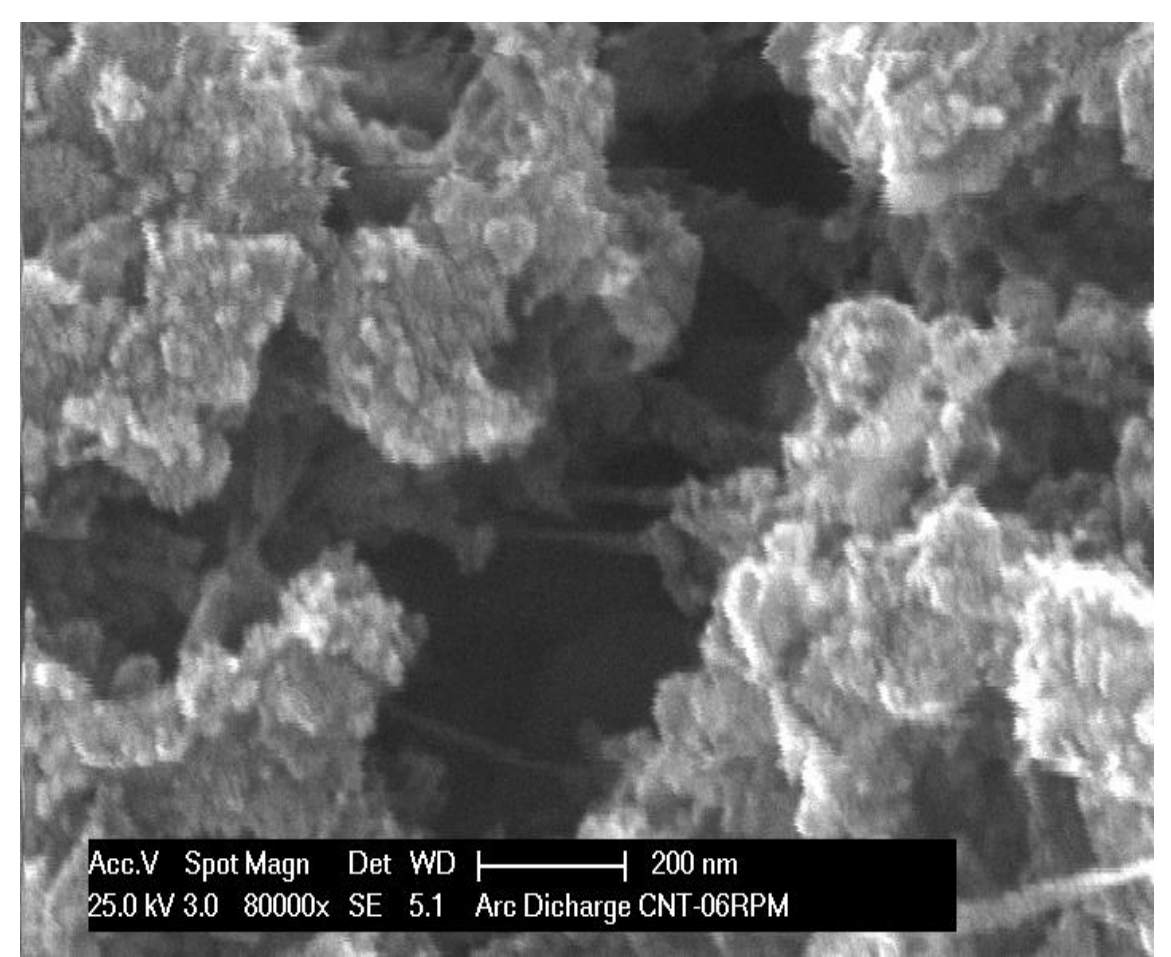

Fig. 1. SEM image of CNT prepared by arc discharge in air atmosphere without catalyst. 


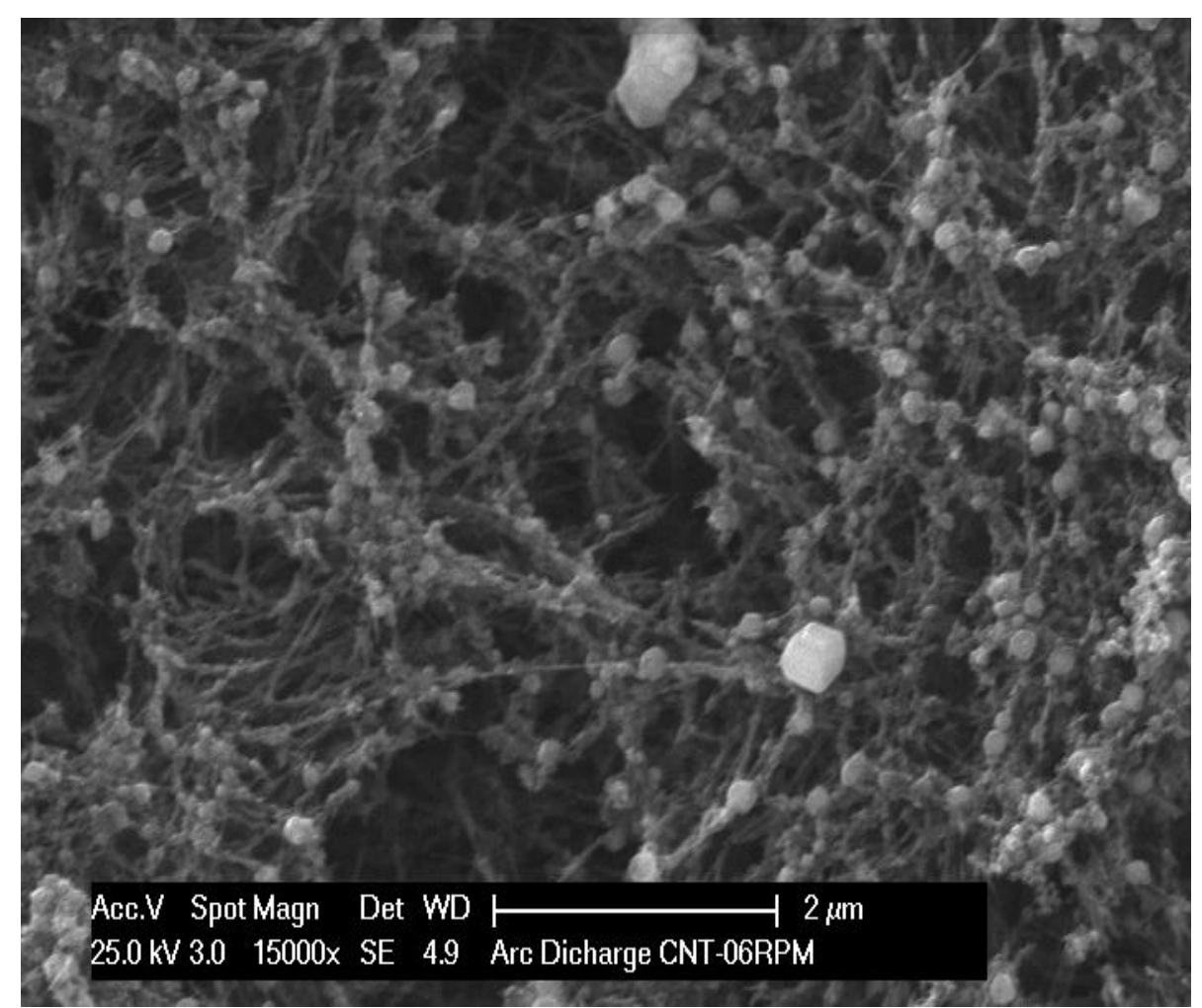

Fig. 2. SEM image of CNT prepared by arc discharge in air atmosphere in presence of amorphous $\mathrm{FeCoB}$ catalyst.

By comparing Fig. 1 and 2, it is obvious that the CNTs yield increased remarkably in presence of FeCoB. The TEM image of the unpurified sample prepared in presence of mentioned catalyst is shown in Fig. 3. Multi-wall carbon nanotubes (MWNTs) of different diameters are formed. The tubes are multiply capped at their terminal end and substantial distortion within the walls that maintain layer integrity. Although the tip of the nanotube was not opened, parts of the walls were broken. It is suggested that ultrasonication during sample preparation enhanced the nanotubes wall distortion which might introduce defects in the nanotubes ${ }^{(16)}$. The CNTs are either straight or bended as observed in the figure by the square. In Fig. 4, the diameter of the tubes is determined from the TEM image of the same sample after strong acidic etching in $6 \mathrm{M}$ $\mathrm{HCl}$ boiled for $2 \mathrm{hr}$. The outer diameter (presented by solid lines) varies from 8 to 10 $\mathrm{nm}$ and the inner diameter (presented by dotted lines) is within 3-4 $\mathrm{nm}$. The number of layers varies from 11-15 layers. Besides the nanotubes some irregular graphite structures are observed (pointed by an arrow) which means that there may be many defects in such structure. 


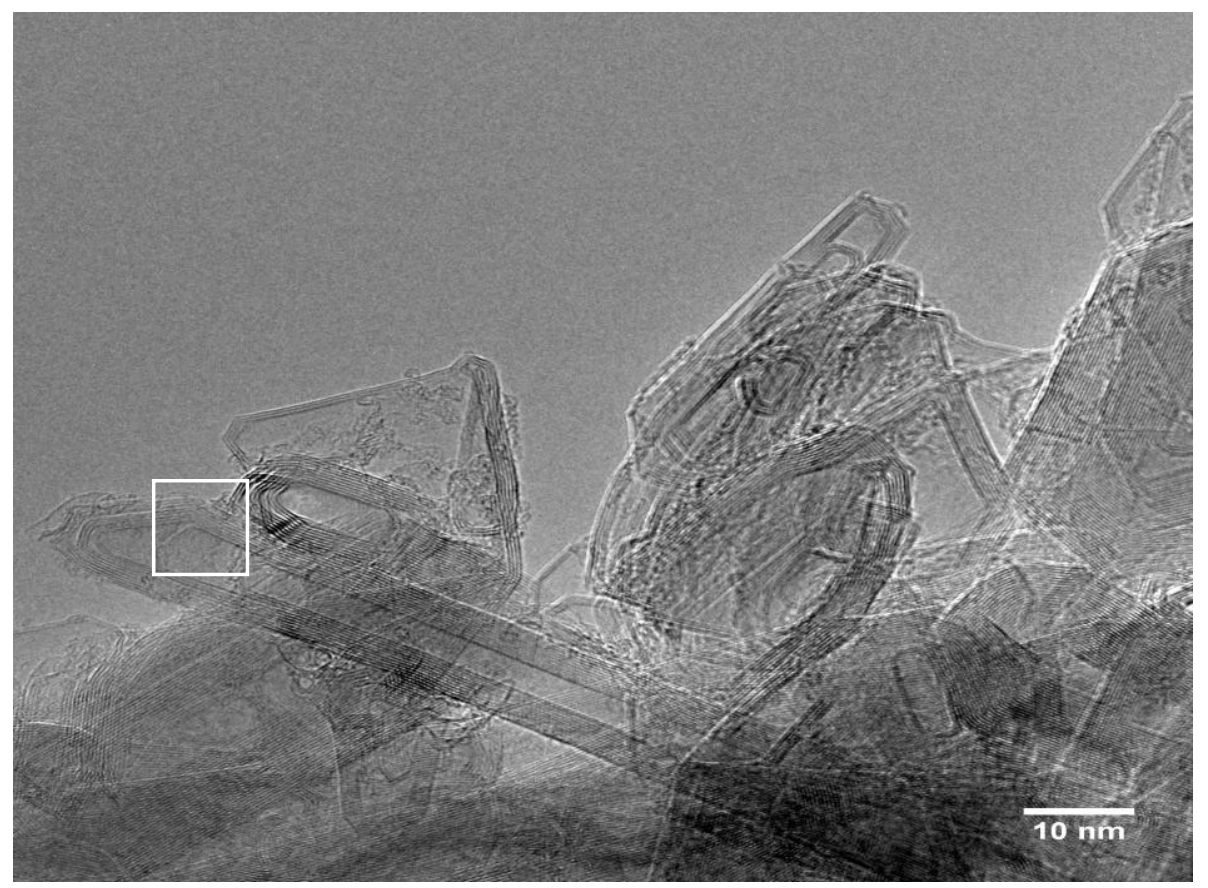

Fig. 3. TEM image of CNT prepared by arc discharge in air atmosphere in presence of amorphous FeCoB catalyst.

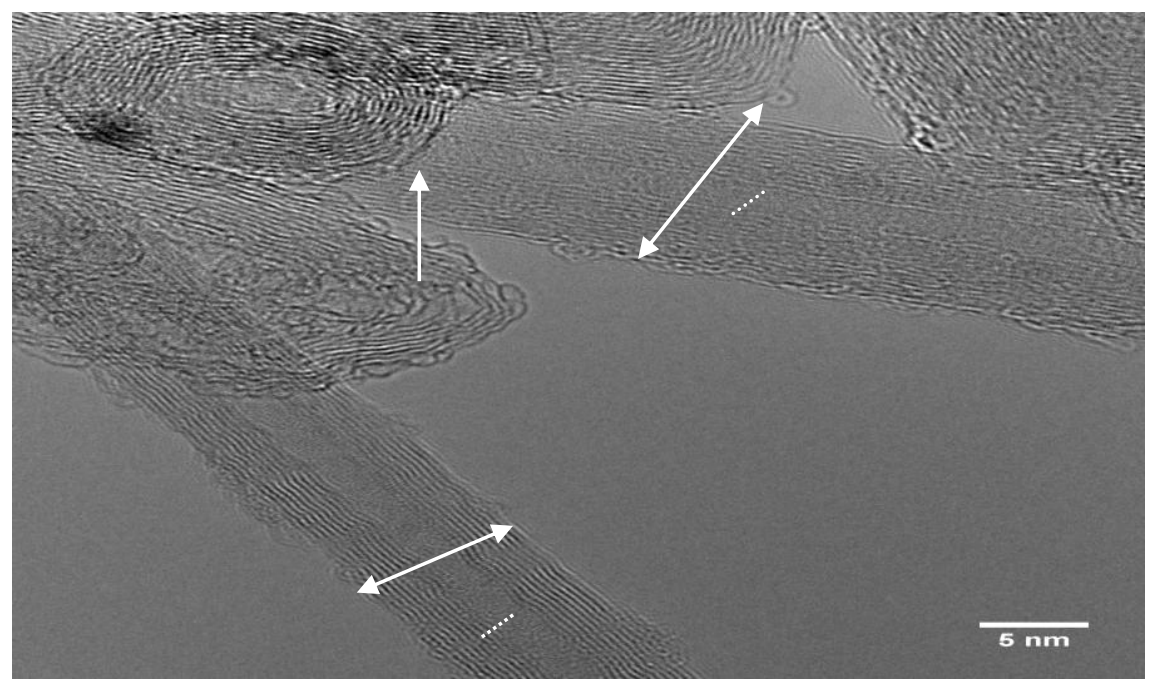

Fig. 4. TEM image of CNT prepared by arc discharge in air atmosphere in presence of amorphous $\mathrm{FeCoB}$ catalyst after etching in $6 \mathrm{M} \mathrm{HCl}$. 
The Raman spectrum of CNTs produced is introduced in Fig. 5. It is typical for the existence of CNTs. It has two characteristic peaks at around 1350 and $1580 \mathrm{~cm}^{-1}$, respectively ${ }^{(17-19)}$. At $1580 \mathrm{~cm}^{-1}$ the peak is identified as the $\mathrm{G}$ band of crystalline graphite. For the graphite like structure but with defects, the peak at $1350 \mathrm{~cm}^{-1}$ is identified as the $\mathrm{D}$ band, which is activated due to defects and disorders of carbonaceous materials. Thus, the increase of the ratio of $I_{D}$ to $I_{G}$ increases, it indicates a high number of defects in the graphite structure, where $I_{D}$ and $I_{G}$ are the measure of the peak intensity of D band and $\mathrm{G}$ band, respectively. This ratio was evaluated from the plot in Fig. 5 as 1.08, which means high number of defects in the graphitized CNTs structure.

Arcing under the same conditions in presence of amorphous Zr-base alloy manually pressed in the hallow hole in the anode has produced a gray fluffy product all over the arcing chamber. The SEM image of the product is shown in Fig. 6. It was not possible to detect nanotubes by SEM, only cubic agglomerated particles and a spherical whiter particles which resembles the Zr-based alloy. The X-ray difractogram of the product is shown in Fig. 7 a. Zirconium carbide phase is formed beside the graphide characteristic phase which may retard the formation of CNTs. On the other hand, no preference formation of any carbide phase is observed in case of using $\mathrm{FeCoB}$ in arc process as clearly seen in Fig. $7 \mathrm{~b}$.

The thermal stability of the CNTs samples prepared in absence and presence of FeCoNi are displayed in TGA curve in Fig. 8. Up to $600^{\circ} \mathrm{C}$ the CNTs prepared in both cases has high resistance towards oxidation. The CNTs prepared without amorphous catalyst is totally decomposed at $900^{\circ} \mathrm{C}$. Also, the CNTs prepared in presence of $\mathrm{FeCoB}$ is entirely decomposed at $900^{\circ} \mathrm{C}$. At such temperature $77 \%$ of CNTs prepared in presence of $\mathrm{FeCoB}$ catalyst decomposed.

The adsorption/desorption rate curves of hydrogen at 20 bar and $-193^{\circ} \mathrm{C}$ for both CNTs with and without FeCoB are shown in Fig. 9. At the beginning of the adsorption curves, there are rapid increase in the amount of hydrogen adsorbed within the first few minutes. In case of CNTs prepared without a catalyst it takes about 5 min. while in case of CNTs prepared with FeCoB it takes about 3 min. Further increase is followed but with slower rate. The hydrogen sorption capacities of CNT prepared without a catalyst and with $\mathrm{FeCoB}$ reach 1.8 and $1.4 \mathrm{wt} \%$, respectively. The desorption curves seem to be not affected by the presence of the FeCoB and full desorption needs more than $40 \mathrm{~min}$.

\section{Conclusions}

Quantitative yield of CNTs is successfully produced by arc discharge method in presence of amorphous $\mathrm{FeCoB}$ as a catalyst. The CNTs prepared are multiwall. It has high thermal resistance towards oxidation till $600^{\circ} \mathrm{C}$ and also towards strong acids. At 20 bar hydrogen and $-193^{\circ} \mathrm{C}$ the amount of hydrogen adsorbed was not enhanced by the presence of $\mathrm{FeCoB}$ and a slight improvement in adsorption kinetics was detected. Arcing in presence of amorphous $\mathrm{FeCoB}$ does not show preferential formation of Carbides as has been displayed in presence of $\mathrm{Zr}$-base amorphous alloys. 


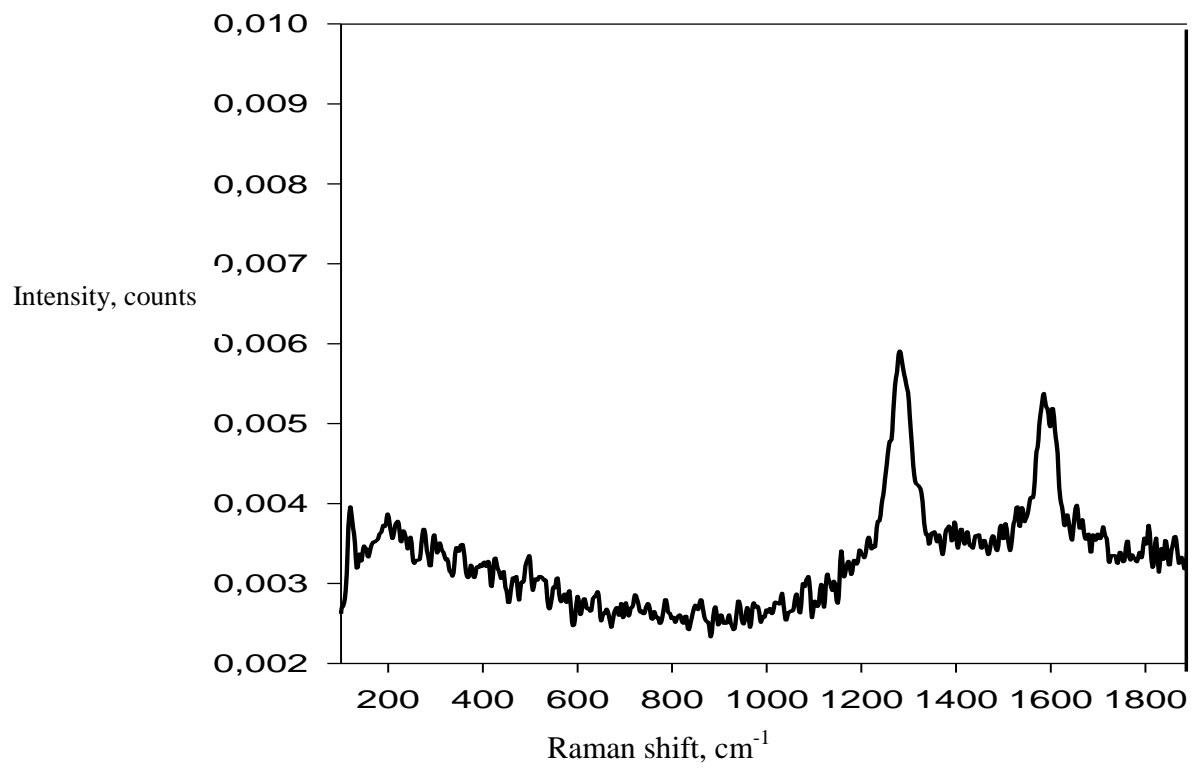

Fig. 5. Raman spectrum of CNT prepared.

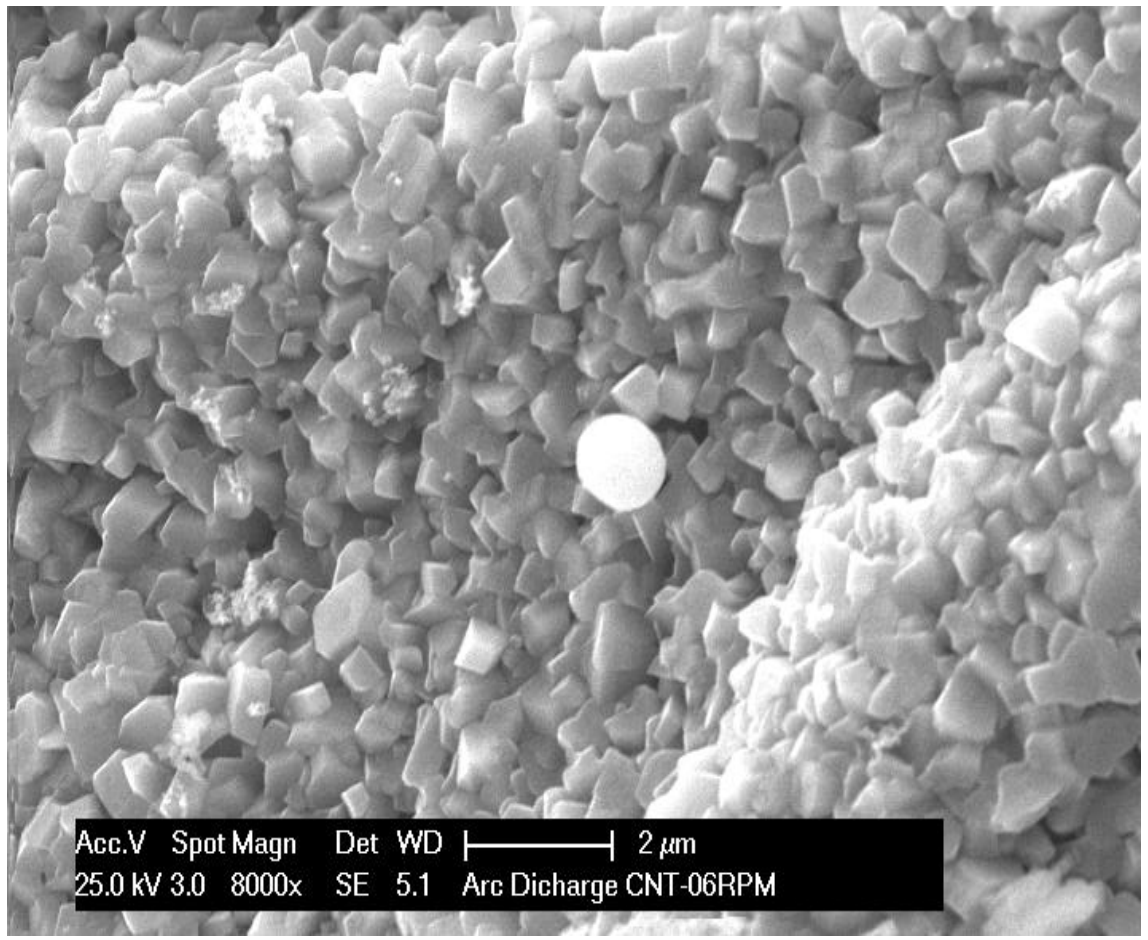

Fig. 6. SEM image of the soot produced by arcing in presence of $\mathrm{Zr}$-base amorphous alloy. 


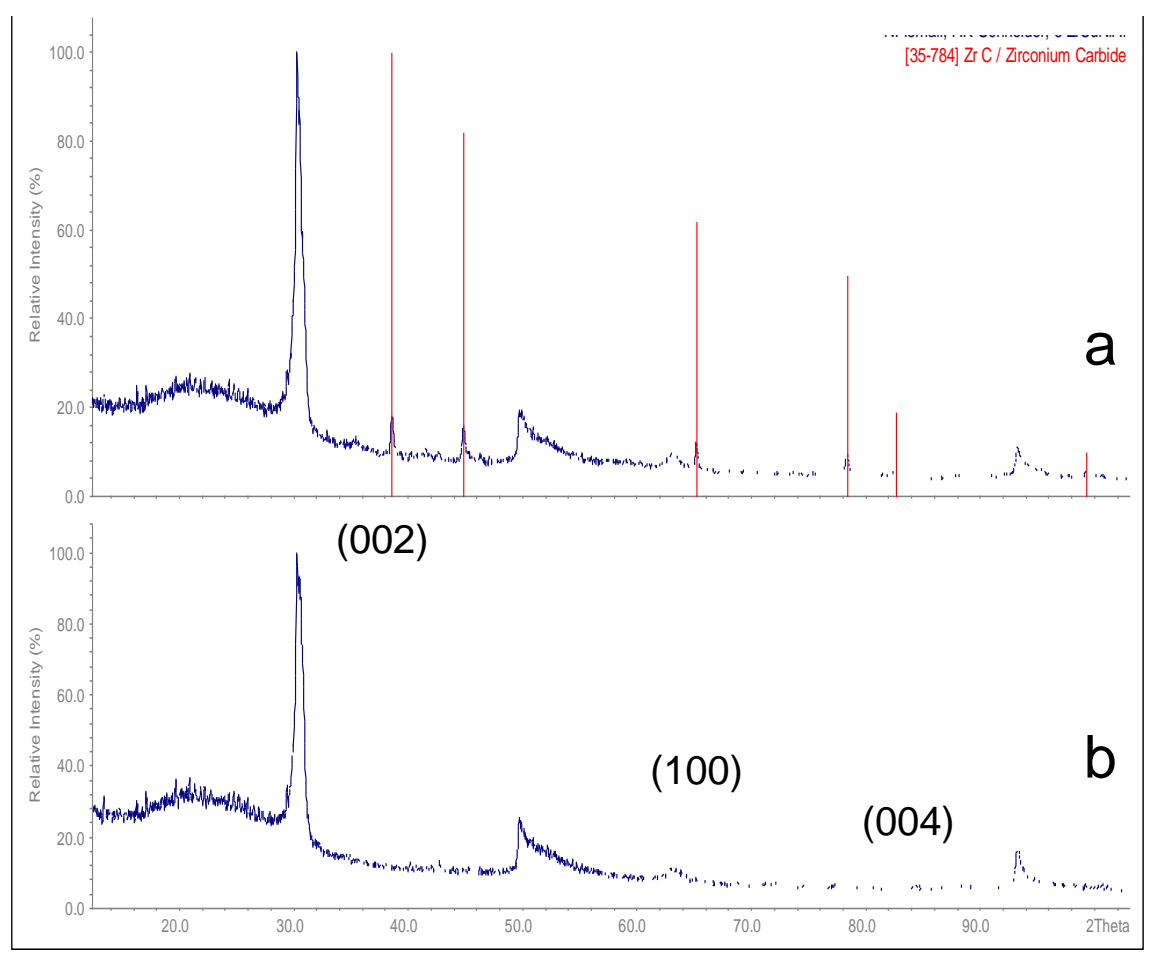

Fig. 7. XRD diffractograms of (a) graphitized CNT in presence of amorphous FeCoB catalyst ; (b) graphide and $\mathrm{ZrC}$.

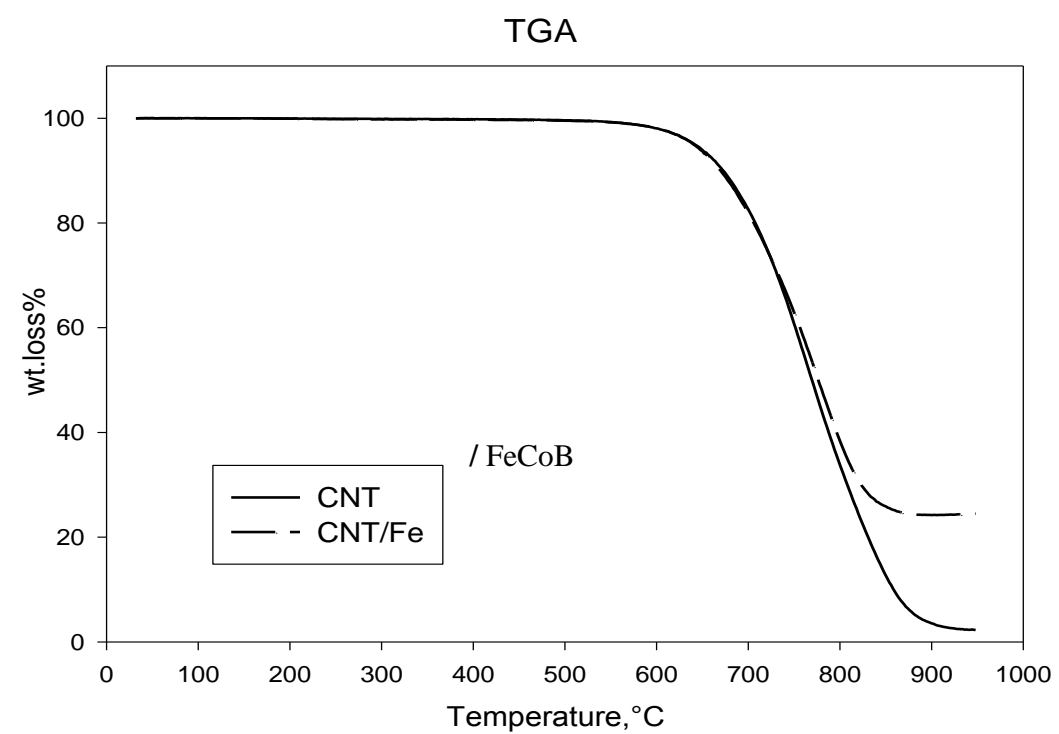

Fig. 8. Themo gravimetric curve of CNT prepared without a catalyst and with FeCoB amorphous alloy.

Egypt. J. Chem. 53, No. 3 (2010) 


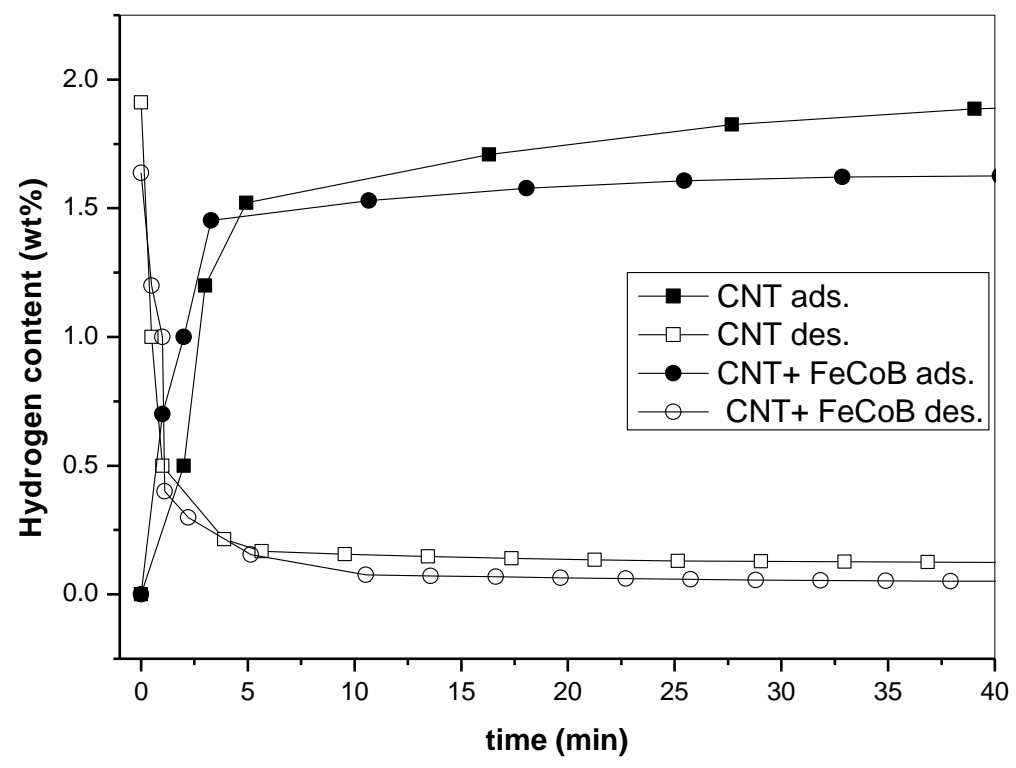

Fig. 9. Hydrogen adsorption / desorption curves of CNT prepared with and without a catalyst $(\mathrm{FeCoB})$.

\section{References}

1. Iijima, S. Nature, 354 (1991) 56.

2. Thess, A. Lee, R. Nikolaev, P. Dai, H. Petit, P. Rabert, J. et al., Science, 273 (1996) 483487.

3. Ren, Z. F. Huang, Z.P. Xu, J.W. Wang, J.H. Bush, P. Siegal, M.P. Science 282 (1998) 1105-1107.

4. Chhowalla, M. Teo, K.B.K. Ducati, C. Rupensinghe, N.L. Amaratunga, G.A. Ferrari, A.C. et al. J. Appl. Phys. 90 (2001) 5308-5317.

5. Xiao, T. Ren, Y. Liao, K. Wu, P. Li, F. and Cheng, H.M. Composites Science and Technology, 68 (14), 2008, 2937-2942.

6. Wu, F.W. Ibrahim, R.N. Das, R. and Singh Raman, R.K. Theoretical and Applied Fracture Mechanics, $\mathbf{5 2}$ (1), 2009, 50-54.

7. Qi-Dan Ling, Der-Jang Liaw, Chunxiang Zhu, Daniel Siu-Hung Chan, En-Tang Kang and Koon-Gee Neoh, Progress in Polymer Science, 33 (10), 2008, 917-978.

8. Fang, F.Z. Xu, Z.W. Zhang, G.X. and Hu, X.T. CIRP Annals - Manufacturing Technology, 58 (1), 2009, 455-458. 
9. Paulo E. Lopes, Ferrie van Hattum, Celeste M.C. Pereira, Paulo J.R.O. Nóvoa, Stefan Forero, Felicitas Hepp and Laurent Pambaguian, Composite Structures, (In Press) 2009.

10. Sunil Kumar Pandey, Rajesh Kumar Singh and Srivastava, O.N. International Journal of Hydrogen Energy, 34 (23), 2009, 9379-9384.

11. Priyanka H. Maheshwari and Mathur, R.B. Electrochimica Acta, 54 (28), 2009, 74767482 .

12. Ajayan, P.M. Ebbesen, T.W. Ichihashi, Iijima, S. Tanigaki, K. Hiura, H. Nature 362 (1993) 522.

13. Paladugu, M. Maneesh, K. Nair, P.K. Haridoss, P. J. Nanosci. Nanotechnol. 5 (2005) 747.

14. Ismail, N. Uhlemann, M. Gebert, A. J. Eckert,Journal of Alloys and Compounds 298 (2000), 146-152.

15. Inoue, A. Masumoto. T. and Saida, J. Metallurgical Transactions A, 19A, 2315 (1988).

16. Hyeon Hwan Kim and Hyeong Joon Kim, Materials Science and Engineering, B 130 (2006) 73-80.

17. Eklund, P.C. Holden, J.M. Jishi, R.A. Carbon, 33 (1995) 959.

18. Sveningsson, M. Morjan, R.E. Nerushev, O.A. Sato, Y. Bäckström, J. Campbell, E.E.B. Rohmund, F. Appl. Phys. A 73 (2001) 409.

19. Chen, K.F. Chen, K.C. Jiang, Y.C. Jiang, L.Y. Chang, Y.Y. Hsiao, M.C. and Chan, L.H. Appl. Phys. Lett. 88 (2006) 193127.

(Received 4 /1/2010;

accepted 16/2/ 2010) 


\section{تحضير وتوصيف انابيب كربونيه نانومتريه باستخدام حفازات صلبه غير متبلوره

\author{
نهله اسماعيل، اسلام حمدي عبد المقصود و عبد الرحمن عبدالله بلوي الـوي

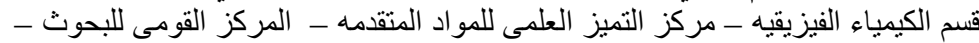

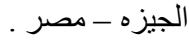

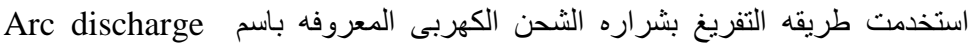
method

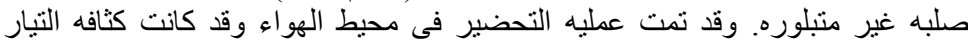

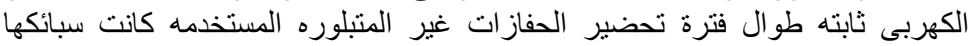

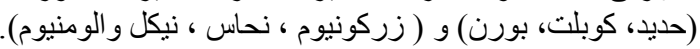

وبعد توصيف الناتج المحضر فى وجود (حديد، كوبلت والبورن) الغير متبلور تبين

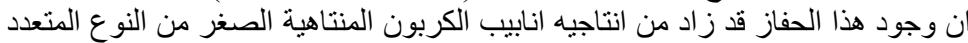

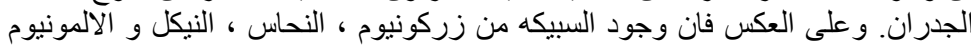

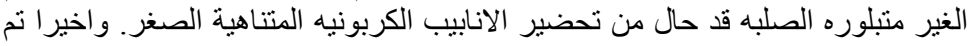

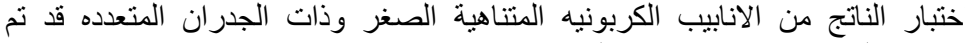
اختبار ها لخاصية امتصاص الأن غاز الهيدروجين. 